Article

\title{
Impact of the Dam Construction on the Downstream Thermal Conditions of the Yangtze River
}

\author{
Tianfu He, Yun Deng *, Youcai Tuo *, Yanjing Yang and Naisheng Liang \\ State Key Laboratory of Hydraulics and Mountain River Engineering, Sichuan University, \\ Chengdu 610065, China; htf853835664@163.com (T.H.); 13281109119@163.com (Y.Y.); \\ 2017323060027@stu.scu.edu.cn (N.L.) \\ * Correspondence: dengyun@scu.edu.cn (Y.D.); tuoyoucai@scu.edu.cn (Y.T.)
}

Received: 2 March 2020; Accepted: 23 April 2020; Published: 24 April 2020

\begin{abstract}
Water temperature is an important factor in aquatic environments. Dam construction, especially the construction of multiple dams in rivers, can greatly affect the downstream water temperature. Several dams, including Wudongde, Baihetan, Xiluodu, Xiangjiaba, Three Gorges, and Gezhouba, have been constructed between Panzhihua and Yichang along the Yangtze River. The aim of this paper was to quantify the impact of these dams on the water temperature downstream. One-dimensional and two-dimensional models were used to simulate the water temperatures, and the results showed that the dams had different cumulative effects on it. For example, in January, after the construction of the Xiangjiaba and Xiluodu dams, the discharge water temperature of Xiangjiaba was $3^{\circ} \mathrm{C}$ higher than the natural conditions, and after the construction of the Baihetan and Wudongde dams was completed, it increased by a further $2{ }^{\circ} \mathrm{C}$. The natural river ran over $416 \mathrm{~km}$ with no dams from the Xiangjiaba dam to the Cuntan Station. With the influence of climate and tributary inflow, the impact of upstream dams on the water temperature was mitigated by more than $48 \%$ at Cuntan Station, displaying a recovery. It seemed that the cumulative effects of dams on the discharge water temperature of the Three Gorges decreased with the increase in the upstream storage capacity from March to May, and the construction of dams even had a negative effect. From September to February of the next year, the cumulative effects increased with the increase of the upstream storage capacity, but only the total storage capacity until a certain level, where no further impact was observed.
\end{abstract}

Keywords: Yangtze River; multiple dams; water temperature; cumulative impact; Chinese sturgeon

\section{Introduction}

Currently, many rivers are fragmented by dams, especially large rivers. Dams play important roles in flood control, electricity generation, irrigation, and other processes [1-4]. In addition to obvious benefits, the construction of dams threatens river ecosystems [5], such as changing hydraulic conditions [6,7], promoting eutrophication, blocking fish migration routes [8,9], and reducing species diversity $[10,11]$. Additionally, the construction of dams can change the water temperature in a basin. Changes in water temperature may negatively impact the river ecosystems, and as the number of dams increases, this negative impact may accumulate [12-14].

Water temperature is an important ecological factor in habitats [15-17]. Some fish species are very sensitive to water temperature; they spawn only when the water temperature reaches a certain range $[18,19]$. Stratification usually occurs in reservoirs, especially large reservoirs [20,21]. The discharge water temperature is usually significantly different from that before the dam construction [22]. Recently, the negative effects of dam construction on the water temperature of downstream rivers have attracted widespread attention. A few examples of these effects can be seen at the Flaming Gorge Dam, the Gathright Dam, and the Shasta Dam in the United States, and the Burrendong Dam and the Keepit Dam 
in Australia [23-25]. Dam construction has been found to lead to changes in the thermal regime [26]. In many rivers, researchers pay attention to the fact that the discharge water temperature of a reservoir is lower than that before the construction of the dam in spring and summer. The variations in the thermal regime modify habitat conditions and biological communities [24]. For example, in some cases, cold-adapted fish species have been found to displace native species [27]. In addition, the discharge water temperature of a reservoir may be higher than that before dam construction. This impact may also affect the ecology in the river. For example, some species spawn only when the water temperature is below a certain level [28-32].

Multiple dams are usually constructed in rivers, and the dams may produce a cumulative effect on downstream water temperature [16]. Liu L.F.'s research results showed that the higher the degree of hydropower development, the greater the cumulative impact on the river water temperature, in the Lancang River Basin. The cumulative impact of five dams is greater than that of three dams, and larger dams contribute more to the cumulative effect than smaller dams [12]. The same trend has been observed in other rivers [14]; as the number of dams increases, the accumulation effect on water temperature becomes more obvious.

The Yangtze River is one of the largest rivers in the world, and it is rich in aquatic species. Four dams have been built on this river, and two dams are under construction, with more dams possibly planned further upstream in the future. In 2012, Liang, R.F. used a two-dimensional water temperature model to predict the accumulative impact of the dams (including Xiangjiaba, Xiluodu, Baihetan, and Wudongde) on the water temperature [16]. According to the research results, the construction of the dams had a cumulative effect on the discharge water temperature of the Xiangjiaba. The thermal conditions further downstream of the Xiangjiaba dam were not analyzed. There are many fish resources in the Yangtze River, including the Chinese sturgeon, an endangered species. It is important to determine how the water temperature downstream shifts as the number of dams increases. As the total storage capacity continues to increase, will the impact of dams on water temperature reach a limit, or will the impact be moderated? To the authors' knowledge, to date there has been no relevant research conducted on this topic; thus, the purpose of this paper is to address this gap. Through numerical simulation, the authors studied the influence of the dams on the thermal conditions in the river downstream and the causes of the variations in the downstream thermal conditions with the increasing number of dams.

\section{Materials and Methods}

Several objectives were addressed in this study. The one-dimensional model was verified using measured hydraulic data and water temperature data from 2014. A two-dimensional model was verified using measured water temperature data from a reservoir in 2013. The one-dimensional model was used to simulate the water temperature in the natural river reach. The water temperature in the reservoirs was simulated by the two-dimensional model. The effects of the dams on the water temperature in the river reach were analyzed. The effects of dam construction on the discharged water temperature in the reservoirs were studied. Based on the changing trend of downstream water temperature with the increase of the upstream total storage capacity, we predicted the trend of downstream water temperature when more dams are built in the future.

\subsection{Study Area}

The river reach between the Wudongde (WDD) and Gezhouba (GZ) dams on the Yangtze River was the study area, with a length of approximately $1800 \mathrm{~km}$; shown in Figure 1. As shown in Table 1, since the 1980s several dams have been built on the main channel of the Yangtze River, including the Gezhouba (GZ), the Three Gorges (TGD), the Xiangjiaba (XJB), and the Xiluodu (XLD) dams. Additionally, two dams are under construction upstream of the XLD: Baihetan (BHT) and Wudongde (WDD). The Gezhouba is a relatively small reservoir at $47 \mathrm{~m}$ high and has a total storage capacity of 
$15.8 \times 108 \mathrm{~m}^{3}$, and the others are all large reservoirs, with heights of more than $150 \mathrm{~m}$ and storage capacities of more than $50 \times 108 \mathrm{~m}^{3}$.

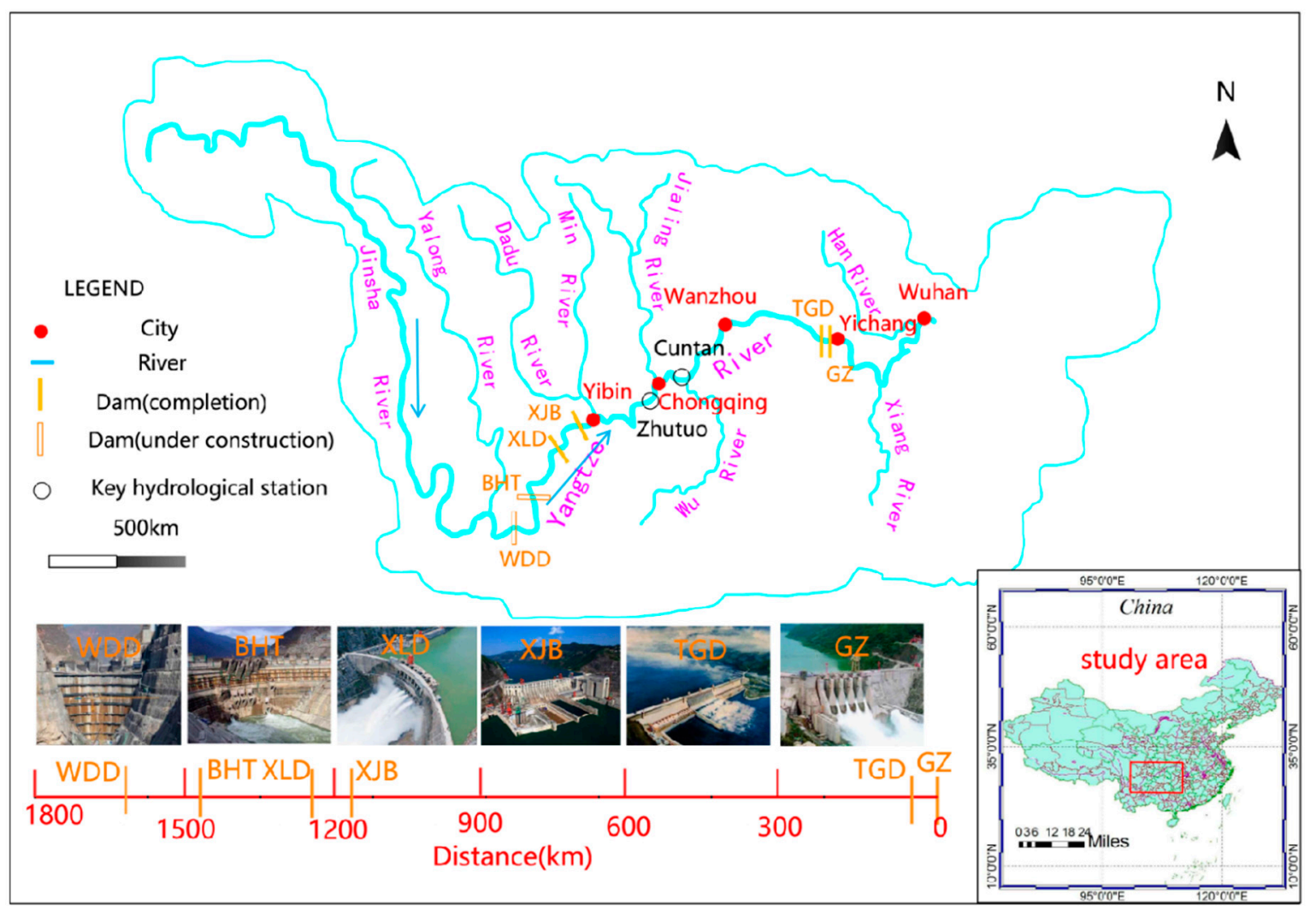

Figure 1. Locations of the dams in the Yangtze River. (GZ: Gezhouba, TGD: Three Gorges, XJB: Xiangjiaba, XLD: Xiluodu, BHT: Baihetan, and WDD: Wudongde).

Table 1. The main characteristics of the six dams of interest and their corresponding acronyms.

\begin{tabular}{ccccc}
\hline Dam & Acronym & Completion Time & Storage Capacity $\left.\mathbf{( 1 0 8} \mathbf{~ m}^{\mathbf{3}}\right)$ & Distance from Gezhouba (km) \\
\hline Gezhouba & GZ & 1982 & 16 & 0 \\
\hline Three Gorges & TGD & 2009 & 393 & 38 \\
\hline Xiangjiaba & XJB & 2012 & 52 & 1100 \\
\hline Xiluodu & XLD & 2014 & 127 & 1250 \\
\hline Wudongde & WWD & 2020 (planned) & 74 & 1650 \\
\hline Baihetan & BHT & 2021 (planned) & 206 & 1450 \\
\hline
\end{tabular}

The construction of these dams will change the flow of downstream river channels, and thermal stratification may occur in these reservoirs. The discharge water temperature from the reservoirs may be significantly different to that before the construction of the dams, and the downstream water temperature will vary. There are several tributaries in the study area (as shown in Figure 1), and they may also have an impact on the water temperature of the Yangtze River.

\subsection{Model Description}

The natural river remains between the XJB dam and Cuntan Station with no dam constructed, therefore the temperature changes only longitudinally, which can be simulated by a one-dimensional hydrodynamic model. The HEC-RAS model, which was developed by the U.S. Army Corps of Engineers Hydrology Engineering Center [33], was used to simulate the water temperature in the river reach from XJB to Cuntan. This hydrodynamic one-dimensional model can simulate hydrodynamics 
and water quality. The heat exchange at the air-water interface involves five components: net solar radiation, longwave radiation, reflective radiation, evaporation heat loss, and sensible heat transfer [34].

From Cuntan to Yichang, the TGD and GZ dams were built in succession. Thermal stratification may appear in the Three Gorges and Gezhouba reservoirs; the two-dimensional model can simulate the water temperature distribution in the longitudinal and vertical directions of the reservoirs. The water temperature of the TGD and GZ dams was simulated using the CE-QUAL-W2 model, which is a horizontally averaged two-dimensional hydrodynamic and water quality model that has been successfully applied to many river systems and was also developed by the U.S. Army Corps of Engineers [35]. CE-QUAL-W2 is based on the finite difference solution of laterally averaged equations of fluid motion, including: (a) hydrostatic pressure; (b) the free water surface; (c) horizontal momentum; (d) continuity; (e) constituent transport; and (f) the state equation of density. The inlet boundary conditions are the inflow discharge and water temperature at the reservoir tail, the outlet boundary condition is the outflow discharge, and the surface boundary conditions are based on environmental factors related to the reservoir water surface, including the air temperature, solar radiation, wind speed, humidity, and cloud cover [36,37].

\subsection{Methods}

The HEC-RAS model was verified by comparing the simulated water level and the water temperature with the measured data of the natural river between XJB and Cuntan. The calculation domain from $\mathrm{XJB}$ to Cuntan is $416 \mathrm{~km}$, and it was divided into 120 sections with a cross section spacing of $0.5-2 \mathrm{~km}$. The upstream boundary conditions included the outflow and the discharge water temperature of XJB. The downstream boundary condition was the water level at Cuntan, and the meteorological data from the Yibin Meteorological Station and the Chongqing Meteorological Station in 2014 were used as meteorological boundary conditions. In the hydrodynamic simulation with the HEC-RAS model, the value of the riverbed roughness was the key parameter, and the roughness in this paper ranged from 0.035 to 0.051 .

The CE-QUAL-W2 model was verified using measured water temperature data from the TGD reservoir in 2013. The calculation domain of the TGD reservoir has a length of $600 \mathrm{~km}$ from Cuntan to the dam site. The simulated domain was divided into 938 (longitudinal) $\times 86$ (vertical) rectangular grids with sizes of 300-700 $\mathrm{m}$ in the horizontal direction and $1 \mathrm{~m}$ in the vertical direction. The authors used the measured discharge water temperature data from November 2012 to June 2013 from the TGD reservoir to verify the accuracy of the water temperature model.

In this paper, some metrics are used to describe the seasonal and annual changes in the thermal regime, including annual average water temperature, extreme water temperatures, occurrence time of the highest and lowest water temperatures, the difference between the discharged water temperature from the reservoirs and the water temperature before the dam construction, and the seasonal delays in water temperature.

The change in the discharge water temperature in the XJB dam may have influenced the water temperature of the downstream river reach as well as the water temperatures of the TGD and GZ reservoirs; therefore, we analyzed this effect. To study the influence caused by the construction of dams on the downstream water temperature of the Yangtze River, we analyzed the influence in four construction periods (Table 2). The changes of the water temperature in the natural river channel and the changes of the inflow and discharge water temperature of TGD were analyzed to quantify the impact of the upstream dam construction on the downstream thermal regime. Guo W.X.'s research results showed that GZ had little effect on water release temperatures, and the discharge water temperature of TGD was essentially the same as that of the GZ [38]; therefore, we did not simulate the water temperature of GZ. 
Table 2. The four periods of dam construction on the Yangtze River.

\begin{tabular}{ccccccc}
\hline Period & Years & & \multicolumn{3}{c}{ Dams } \\
\hline 1st & Before 2003 & & & GZ & & \\
2nd & 2009-2012 & GZ + TGD & XJB & XLD & & \\
3rd & 2014-2020 & GZ + TGD & XJB & XLD & & \\
4th & After 2020 & GZ + TGD & XJB & XLD & BHT & WDD \\
\hline
\end{tabular}

\section{Results and Discussion}

\subsection{Model Validation}

To verify the accuracy of the models, the hydrodynamics and water temperatures of the river reach from the XJB dam to Cuntan and the TGD reservoir were simulated and compared to the measured data. We considered the impact of tributaries (including the Min River, Tuo River, Jialing River, and Wu River) on the hydrodynamics and water temperature of the main channel of the Yangtze River.

Figure 2 shows that the simulated results of the HEC-RAS model were in good agreement with the measured data. The average difference between the simulated water level and the measured water level (simulated data minus measured data) at Zhutuo Station was $0.3 \mathrm{~m}$, the difference in the water temperature range at Cuntan Station was $-0.4 \sim 0.3{ }^{\circ} \mathrm{C}$, the average difference was only $0.2{ }^{\circ} \mathrm{C}$, and the simulated water temperature was lower than the measured values. The HEC-RAS model can accurately simulate the changes of hydrodynamic conditions in the study domain, and the heat balance under the influence of atmospheric heat exchange and tributaries inflow can also be effectively simulated.
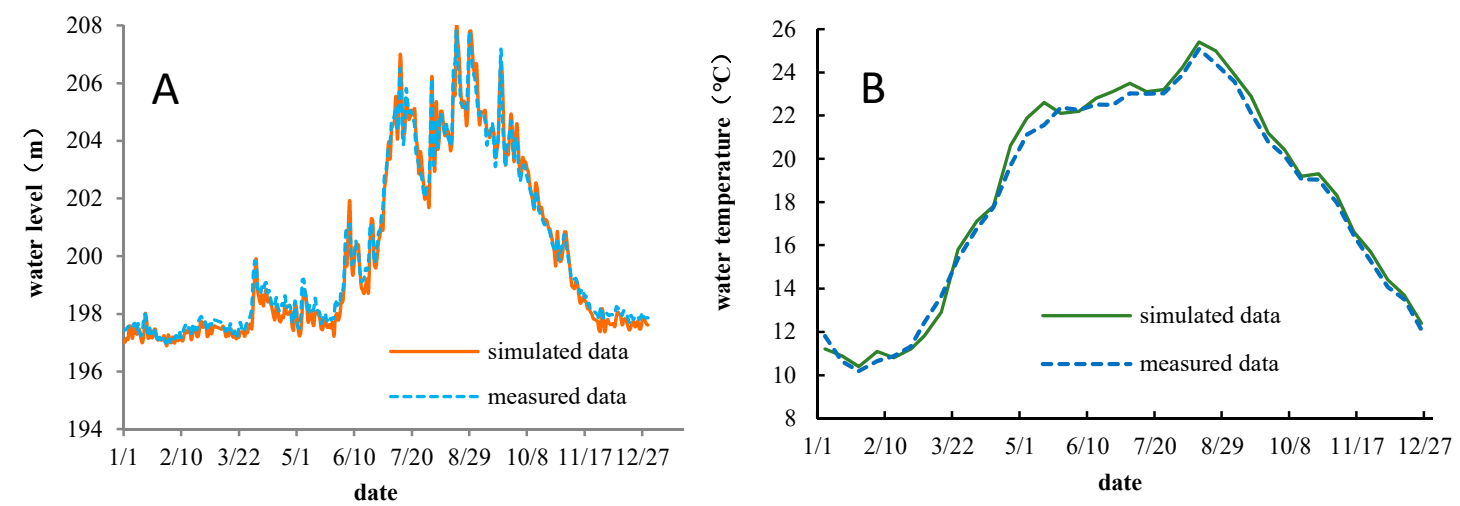

Figure 2. HEC-RAS model verification. (A) The water level at Zhutuo in 2014. (B) The water temperature at Cuntan in 2014.

As shown in Figure 3, the simulated water temperature in the TGD reservoir was compared to the measured data on 28 March 2013. The results showed that the simulated water temperatures of the CE-QUAL-W2 model agreed well with the measured data. The distribution of the water temperature in the longitudinal and vertical directions were accurately simulated, and the average difference between the simulated data and measured data was only $0.2{ }^{\circ} \mathrm{C}$. Figure 4 shows a comparison of the simulated discharged water temperatures of TGD and the measured data. The difference in the water temperature was -0.6 to $0.5^{\circ} \mathrm{C}$, the average difference was only $0.1^{\circ} \mathrm{C}$, and the simulated water temperature was lower than the measured values. The CE-QUAL-W2 model can effectively simulate the changes in water temperature, and the seasonal delay of water temperature due to reservoir impoundment. 


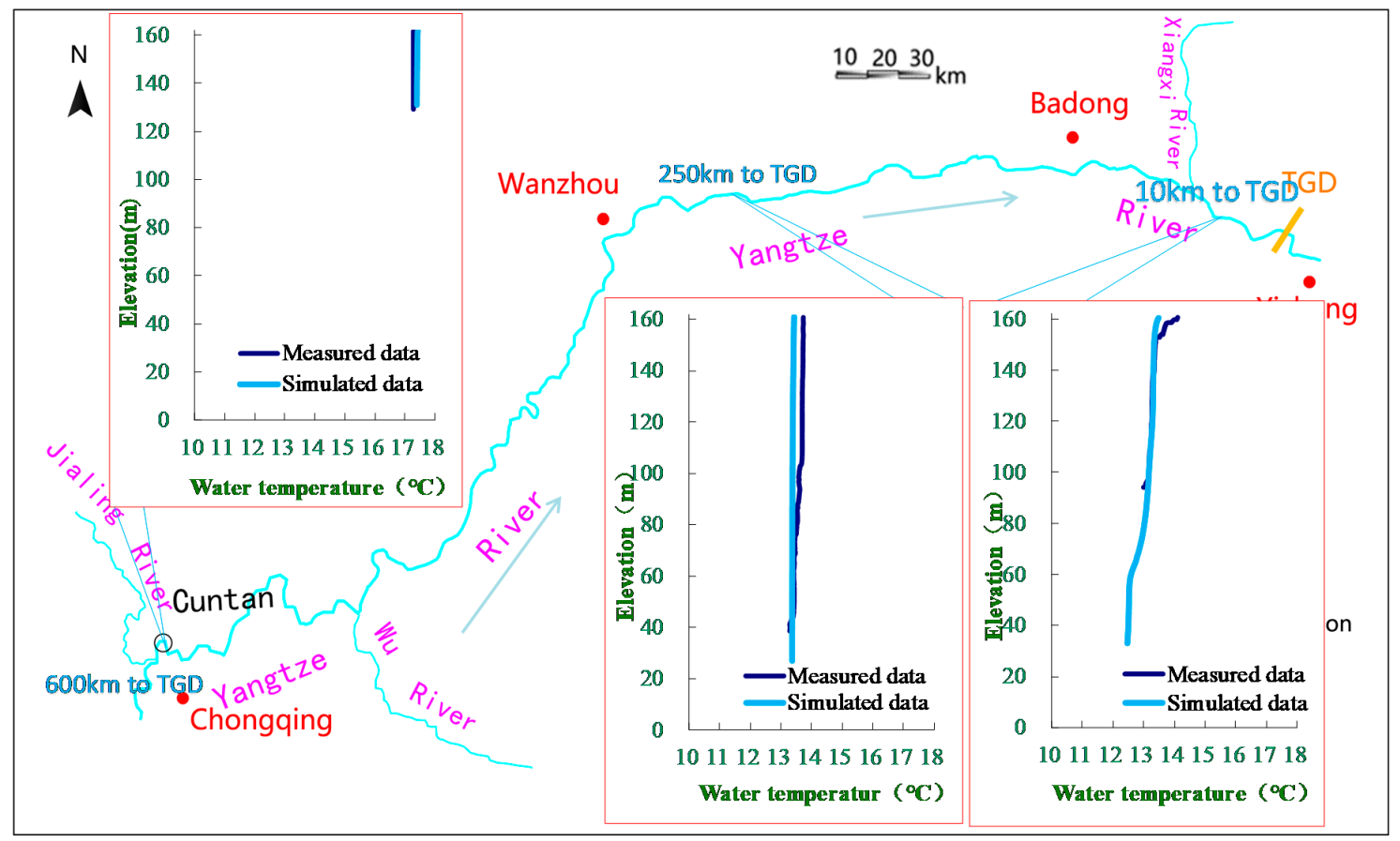

Figure 3. Comparison of simulated and measured water temperatures in the Three Gorges Reservoir on 28 March 2013.

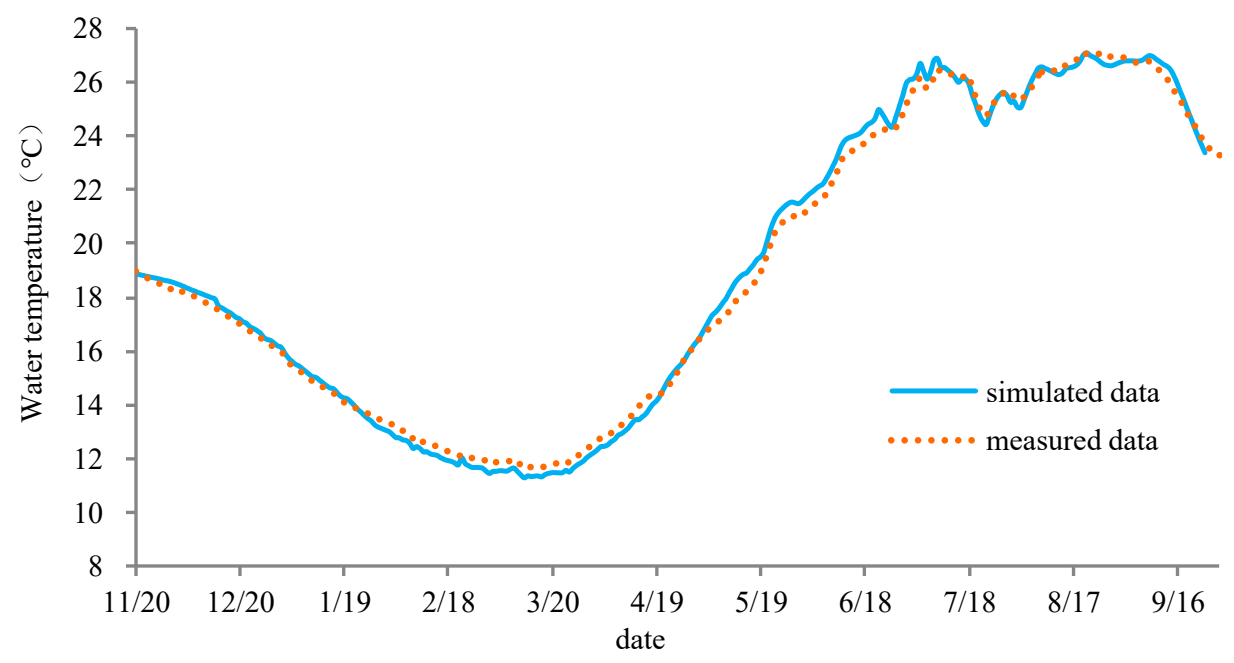

Figure 4. Comparison of the simulated and measured temperatures of water discharged from the TGD (from 20 November 2012 to 9 December 2013).

\subsection{The Discharge Water Temperature of XJB}

After the construction of XJB and XLD (in the 3rd period), thermal stratification occurred in the $\mathrm{XJB}$ reservoir (as shown in Figure 5), and the discharge water temperature of $\mathrm{XJB}$ changed significantly compared to that before the dam was built (in the 1st and 2nd periods). For example, its range reduced, and the appearance time of the extreme value was delayed (as shown in Figure 6). The highest and lowest monthly average water temperatures before the construction of the dams were $22.9{ }^{\circ} \mathrm{C}$ (in August) and $12.4^{\circ} \mathrm{C}$ (in January), respectively. After the XJB and XLD dams were constructed (in the $3 \mathrm{rd}$ period), the highest and lowest values were closer to the average water temperature, at $22.6{ }^{\circ} \mathrm{C}$ and $13.8^{\circ} \mathrm{C}$, respectively. The lowest water temperature appears in March, with a delay of two months compared to that in the 1st and 2nd periods. Moreover, from March to July, lower-temperature water was discharged; the average difference between the discharge water temperature in the 3rd period and 
that in the 1 st period was $2.1^{\circ} \mathrm{C}$, and the maximum difference was $3.7^{\circ} \mathrm{C}$ (in April). Higher-temperature water was discharged during November to January of the following year; the average difference was $2.8^{\circ} \mathrm{C}$, and the maximum difference was $3.3^{\circ} \mathrm{C}$ in December.
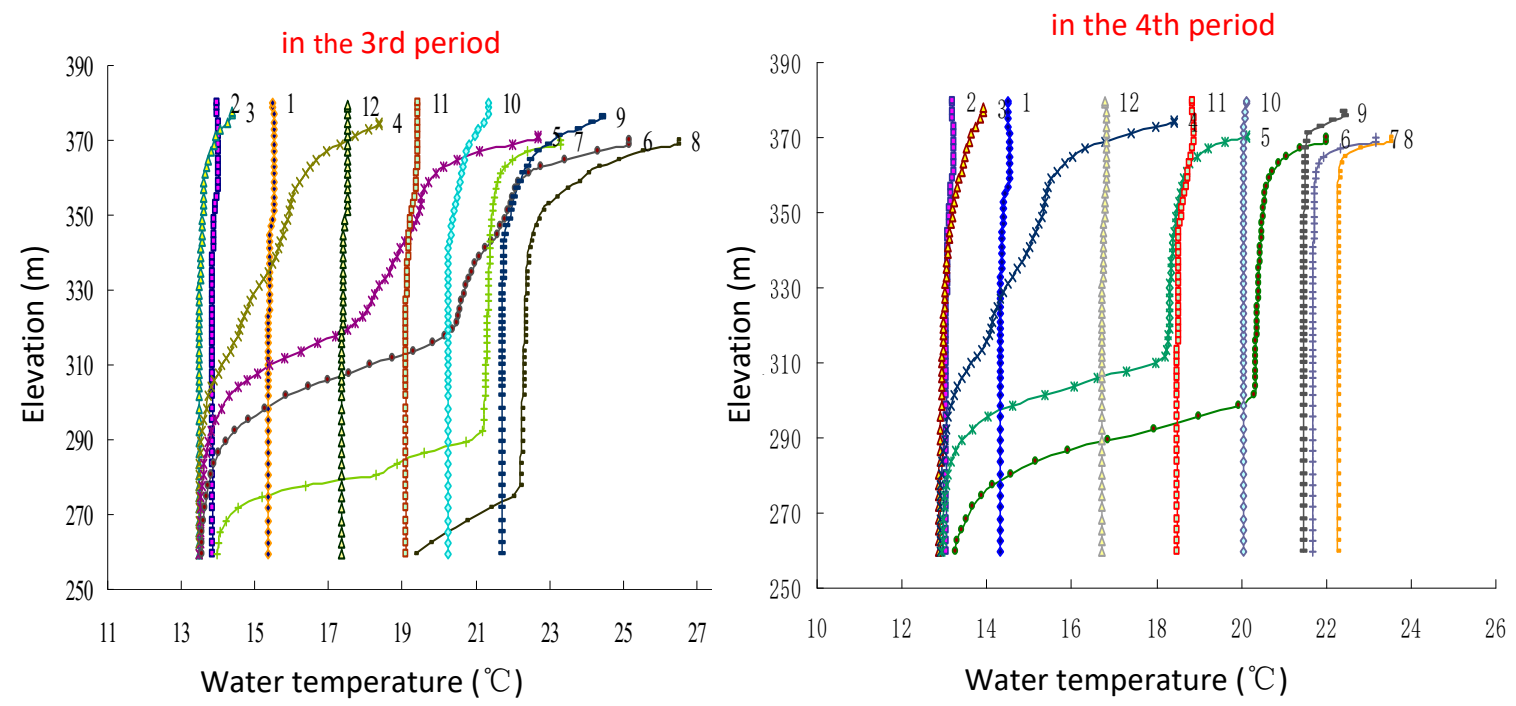

Figure 5. Vertical water temperature distribution in front of the XJB dam (1: January; 2: February; 3: March; 4: April; 5: May; 6: June; 7: July; 8: August; 9: September; 10: October; 11: November; 12: December).
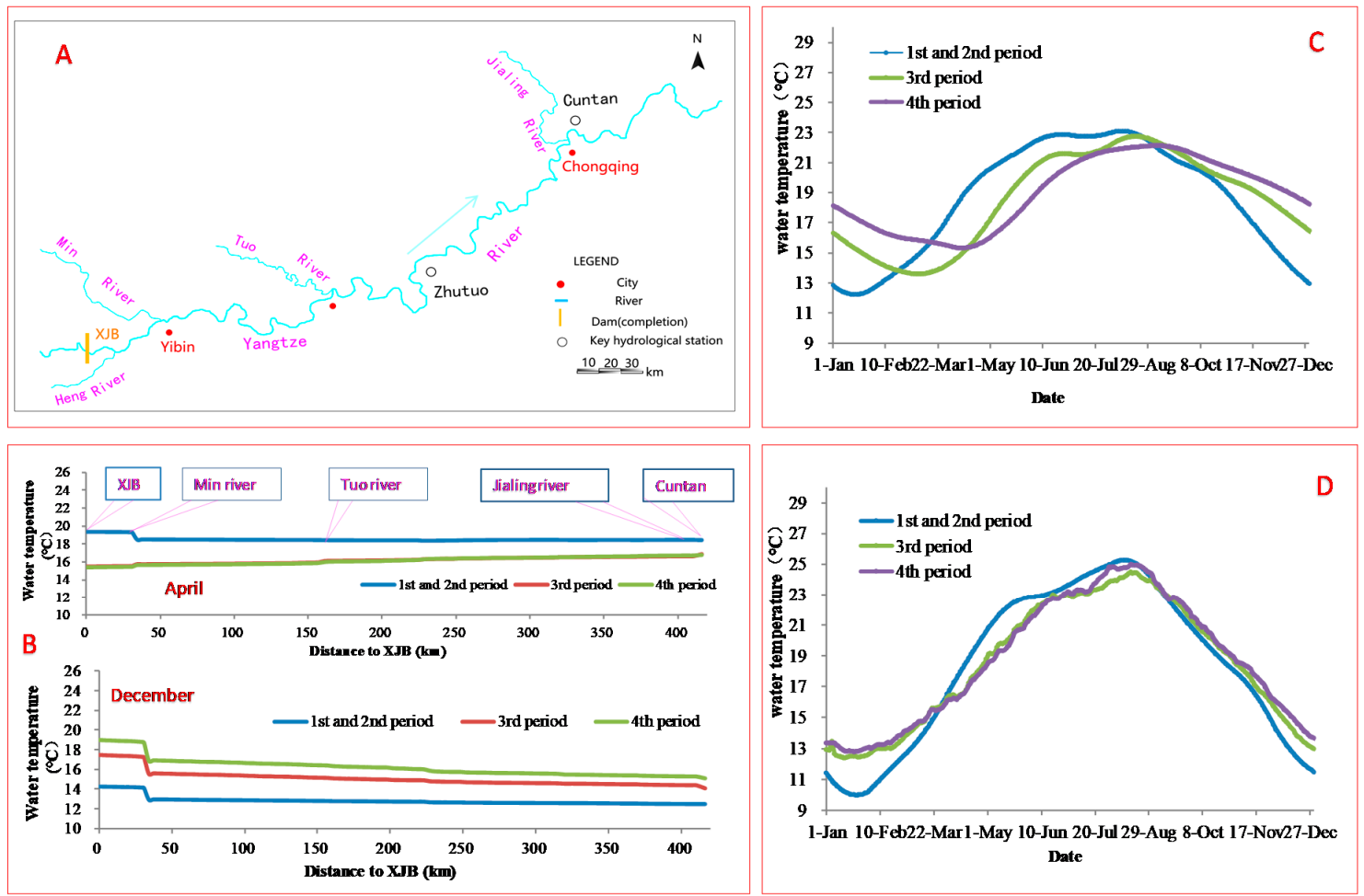

Figure 6. The simulated results of water temperature between $\mathrm{XJB}$ and Cuntan over the four periods. (A): The calculation domain. (B): The water temperature along the river between Xiangiaba and Cuntan in April and December. (C): Daily water temperatures at XJB. The water temperatures in the 1st and 2nd periods are the average daily water temperatures measured from 1984 to 2012; the water temperatures in the 3rd and 4th periods are the simulated data. (D): Daily water temperatures at Cuntan; the water temperatures are simulated data. In the 1st and 2nd periods, XJB had not yet been completed, and there was no dam upstream of Cuntan; in the 3rd period, XJB and XLD had been completed. In the 4 th period, XJB, XLD, BHT, and WDD had been completed. 
The construction of the WDD and BHT dams (in the 4th period) had a further cumulative impact on the discharge water temperature of the XJB dam. The range of discharge water temperature was further reduced compared to that in previous periods, and the highest and lowest monthly average values were $22{ }^{\circ} \mathrm{C}$ (in August) and $15.5^{\circ} \mathrm{C}$ (in April), respectively. Lower-temperature water was discharged from April to August, with time delayed by one month compared to that in the 3rd period; the average discharge water temperature was $2.6^{\circ} \mathrm{C}$ lower than that in natural conditions, and there was a further decrease of $0.5^{\circ} \mathrm{C}$ compared to that in the $3 \mathrm{rd}$ period. In May and June, the cumulative effect was the most severe, with further decreases of $1.8^{\circ} \mathrm{C}$ and $1.5^{\circ} \mathrm{C}$ compared to those in the 3rd period, respectively. From September to March of the next year, the discharge water temperature of $\mathrm{XJB}$ increased by an average of $1.3^{\circ} \mathrm{C}$ compared to that in the $3 \mathrm{rd}$ period. In the 4 th period, the impact time of higher-temperature water was also delayed by one month compared to that in the 3rd period.

\subsection{Impact of Dams on the Inflow Water Temperature of TGD}

There is a natural river reach with a total length of $416 \mathrm{~km}$ from the XJB dam to Cuntan with no dam. Figure 6 compares the water temperature in the four periods at XJB and Cuntan, and the simulated results show that, with the influence of climate and tributary inflow, the impact of dams on water temperature displayed a recovery at Cuntan (the tail of the Three Gorges reservoir). The higher-temperature water and lower-temperature water discharged from XJB flows along the river reach. After flowing through the $416 \mathrm{~km}$ channel, the impacts of dam constructions on water temperature were obviously weakened at Cuntan, but the effects did not completely disappear. The influence of the upstream dams on the water temperature will affect the water temperature of TGD. At Cuntan, the average difference between the water temperature in the 3rd period and that in the 1st period was $0.7{ }^{\circ} \mathrm{C}$, with a reduction of $1.1^{\circ} \mathrm{C}$ compared to the difference at $\mathrm{XJB}$, and $61 \%$ of the impact caused by upstream dams was recovered. Notably, there was a recovery of $2.4^{\circ} \mathrm{C}$ in April, and there was a recovery of $2.2^{\circ} \mathrm{C}$ in December. After the construction of the BHT and WDD dams (in the 4th period), the average difference between the water temperature in the 4th period and the natural condition was $2.5^{\circ} \mathrm{C}$ at $\mathrm{XJB}$, which is greater than that in the $3 \mathrm{rd}$ period. Under the same meteorological and tributary inflow boundary conditions, the average difference in water temperature was only $1.3{ }^{\circ} \mathrm{C}$ at Cuntan, and $48 \%$ of the impact caused by the dams was mitigated.

\subsection{The Discharge Water Temperature of TGD}

According to the simulation results (as shown in Figure 7), the construction of the TGD had an obvious effect on the water temperature downstream, and the annual average discharge water temperature was $0.2{ }^{\circ} \mathrm{C}$ higher than that before the construction of TGD (in the 1st period), increasing from $18.4{ }^{\circ} \mathrm{C}$ to $18.6^{\circ} \mathrm{C}$. In some months (April, December, and January), the temperature varied by more than $3.0^{\circ} \mathrm{C}$. After the TGD reservoir went into operation, the water in the reservoir flowed more slowly than that in the natural river, and inflowing water at the reservoir tail now takes a longer time to flow to the dam; hence, there was a seasonal delay in the discharge water temperature of TGD compared to that before dam construction. In summer and autumn, the inflowing high-temperature water was stored in the reservoir, and it was discharged after several months. From September to February of the next year, the discharge water temperature of TGD was higher than that before construction of the dam (in the 1st period), and the average temperature increase was $2.4^{\circ} \mathrm{C}$; the maximum temperature increase was in January, when the variation reached $3.4^{\circ} \mathrm{C}\left(10.7-14.1^{\circ} \mathrm{C}\right)$. From March to July, the reservoir discharged lower-temperature water, which was stored in winter. The discharge water temperature was decreased by $2.0^{\circ} \mathrm{C}$ on average, compared to that before the construction of TGD in these months, and the greatest variation was $4.6^{\circ} \mathrm{C}$ in April. Due to the small inflow discharge in winter, the replacement rate of reservoir was small, and the low-temperature water that inflowed in January flowed to the dam site in March; the time when the lowest monthly average water temperature appears delayed by 2 months. In summer, because of the large inflow discharge, the replacement rate of reservoir was greater than that in spring; thus, there was no significant delay 
for the time when the highest monthly average appeared, which was observed in August in the 1st and 2nd periods.

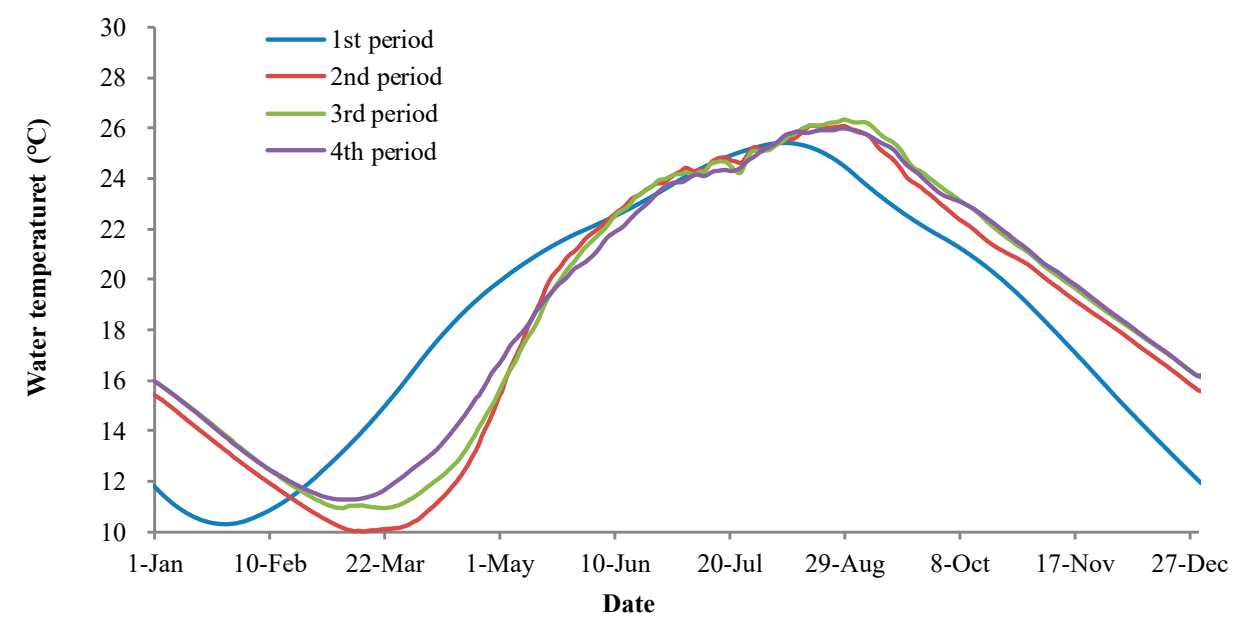

Figure 7. The discharge water temperature of TGD in each construction period.

The construction of the dams upstream in the lower reaches of the Jinsha River (WDD, BHT, XLD, and $\mathrm{XJB}$ ) changed the discharge water temperature of $\mathrm{XJB}$, although with the influence of climate and tributary inflow, the effect was mitigated to some extent at Cuntan, but more than 39\% of the impact still exists, and it will affect the water temperature of TGD (as shown in Figure 5). Therefore, the influence of upstream dam construction on the water temperature of TGD was further studied in this paper.

In the 3rd period, with the construction of the XJB and XLD dams, the inflow water temperature of TGD changed (as shown in Figure 6D, daily water temperatures at Cuntan), and the inflow discharge also changed (as shown in Table 3). From January to May, the water levels in the upstream reservoirs (XJB and XLD) gradually decreased, and the outflow discharge was larger than the inflow discharge, which made the inflow discharge of TGD greater than that in the 2nd period, with an average increase of $523 \mathrm{~m}^{3} / \mathrm{s}$. From June to September, the inflow discharge of TGD was less than that in the 2 nd period, due to upstream reservoir impoundment. XJB and XLD maintained high water levels from October to December, and the inflow of TGD remained almost unchanged in the 2 nd and 3rd periods. With the construction of BHT and WDD (in the 4th period), the changing trend of inflow discharge was similar to that in the 3rd period; from January to May, it was greater than that in 3rd period, but it was less than that in the 3rd period from June to October and remained almost the same from November to December.

Table 3. Monthly inflow discharge and the number of replacements for the Three Gorges Reservoir. The number of replacements is defined as the ratio of total inflow to reservoir capacity per month.

\begin{tabular}{ccccccc}
\hline \multirow{2}{*}{ Month } & \multicolumn{3}{c}{ Inflow Discharge $\left.\mathbf{( m}^{\mathbf{3}} \mathbf{s}\right)$} & \multicolumn{2}{c}{ Number of Replacements } \\
\cline { 2 - 7 } & 2nd Period & 3rd Period & 4th Period & 2nd Period & 3rd Period & 4th Period \\
\hline January & 4474 & 4985 & 5246 & 0.35 & 0.39 & 0.41 \\
February & 4155 & 4700 & 5418 & 0.31 & 0.35 & 0.41 \\
March & 5202 & 5738 & 6389 & 0.46 & 0.51 & 0.57 \\
April & 6723 & 7371 & 8265 & 0.60 & 0.66 & 0.74 \\
May & 11,085 & 11,462 & 12,802 & 1.19 & 1.23 & 1.37 \\
June & 15,436 & 14,747 & 14,718 & 1.98 & 1.89 & 1.89 \\
July & 30,133 & 30,106 & 27,156 & 3.72 & 3.71 & 3.35 \\
August & 20,703 & 20,758 & 20,596 & 2.61 & 2.62 & 2.60 \\
September & 20,323 & 18,523 & 18,185 & 1.97 & 1.80 & 1.77 \\
October & 14,536 & 14,495 & 13,883 & 1.13 & 1.12 & 1.07 \\
November & 8765 & 8790 & 8670 & 0.62 & 0.62 & 0.61 \\
December & 5570 & 5538 & 5881 & 0.41 & 0.41 & 0.43 \\
\hline
\end{tabular}


Additionally, the influence of upstream dams (XJB, XLD, BHT, and WDD) on the XJB discharge water temperature was evident and continued to affect the water temperature of TGD. Under the combined influence of the inflow discharge and inflow water temperature, the discharge water temperature of the TGD changed significantly.

As shown in Figure 8, in the 2nd period, the discharge water temperature of the TGD was lower than that before the TGD was built (in the 1st period), from March to July, and upstream dam construction mitigated this effect. In the 3rd period, the inflow discharge of the TGD increased from January to May, and replacement frequency was accelerated, which caused increases in the discharge water temperature of 0.6 and $0.8{ }^{\circ} \mathrm{C}$, respectively, in March and April. The impact of the TGD construction on the thermal conditions in March and April was weakened compared to that in the 2nd period. In May, June, and July, affected by the low-temperature inflow water, the discharged water temperature of the TGD was lower than that in the 2nd period, with an average decrease of $0.3^{\circ} \mathrm{C}$. The average value of the discharge water temperature of the TGD from March to July was $0.2^{\circ} \mathrm{C}$ higher than that in 2nd period. In the 4 th period, after the construction of the BHT and WDD dams, the average discharged water temperature of the TGD increased further from March to July by $0.3{ }^{\circ} \mathrm{C}$. In March, April, and May, the temperature was higher than that in the 3rd period, with increases of $0.5,1.3$, and $0.3^{\circ} \mathrm{C}$, respectively. In June, the discharge temperature was affected by the low-temperature water from the upstream dams, and it was $0.6^{\circ} \mathrm{C}$ lower than that in $3 \mathrm{rd}$ period; this temperature did not change further in July.

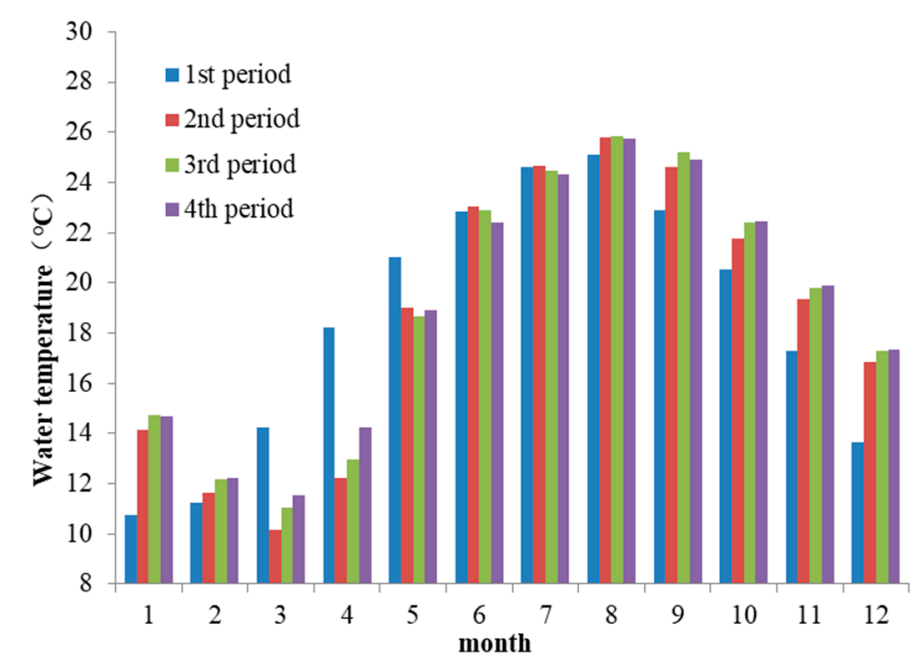

Figure 8. Monthly discharge water temperature of the Three Gorges dam.

After construction of the TGD, the discharge water temperature of the TGD was higher than that before the dam construction (in the 1st period) from September to February of the next year. Additionally, the construction of upstream dams had a further cumulative effect on the water temperature in these months. In the 3rd period, the discharge water temperature of the TGD increased by an average of $0.5^{\circ} \mathrm{C}$, and the variation ranged between 0.4 and $0.6^{\circ} \mathrm{C}$. In the 4 th period, the discharge water temperature remained essentially unchanged compared to that in the $3 \mathrm{rd}$ period.

\subsection{The Trend of Discharge Water Temperature at TGD in the Future}

In the future, more and more dams will be built upstream of the TGD. How will the discharge temperature of the TGD be affected after more dams are constructed? We need to conduct research in this area, because there are many aquatic organisms sensitive to water temperature in the downstream river reaches of the Three Gorges. We therefore performed corresponding analyses and predictions. The relationship between the variation (compared to that in the 1st period) of discharge temperature of the TGD and the total storage capacity of the Yangtze River is shown in Figure 9. The results 
showed that from October to February of the following year, with the construction of the TGD (in the 2nd period), $\mathrm{XJB}$, and $\mathrm{XLD}$ dams (in the 3rd period), the discharge water temperature of the TGD increased as the total storage capacity increased. With the construction of the BHT and WDD (in the 4th period), there was no obvious cumulative effect; the discharge water temperature did not increase further, and the average temperature variation (the discharge water temperature of the TGD minus the natural water temperature at TGD dam) remained at $2.9^{\circ} \mathrm{C}$. From March to July, as the storage capacity increased, the average discharge water temperature increased, and the temperature variation decreased. After TGD operation began (in the 2nd period), the temperature variation was the greatest, and the average variation was $2.0^{\circ} \mathrm{C}$. In the $3 \mathrm{rd}$ period, the average temperature variation was reduced to $1.8^{\circ} \mathrm{C}$, and it was further reduced to $1.5^{\circ} \mathrm{C}$ in the 4 th period. It is important to note that the discharge water temperature of the TGD in June and July decreased with the increase of the total storage capacity, and the temperature variation increased. In the 3 rd period, the variation increased by 0.1 and $0.2{ }^{\circ} \mathrm{C}$, respectively, and it further increased by 0.5 and $0.2^{\circ} \mathrm{C}$, respectively.
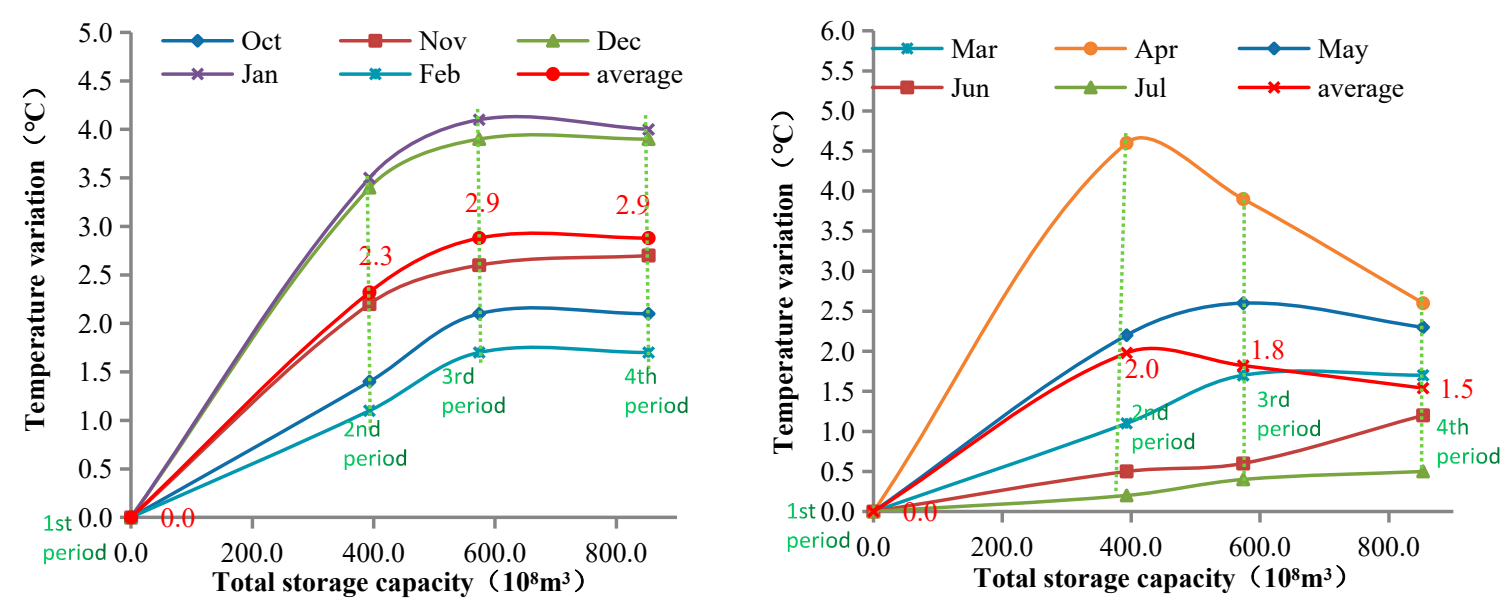

Figure 9. The difference between the discharged water temperature of the TGD and the natural water temperature. The total storage capacity is the sum of the storage capacity of each reservoir. In the 1st period, the total storage capacity is 0 . In the 2 nd period, the total storage capacity is $393 \times 10^{8} \mathrm{~m}^{3}$. In the $3 \mathrm{rd}$ period, the total storage capacity is $574 \times 10^{8} \mathrm{~m}^{3}$. In the 4 th period, the total storage capacity is $853 \times 10^{8} \mathrm{~m}^{3}$.

We can conclude that, from October to February, the discharge water temperature of TGD increased with the increase in the storage capacity of the Yangtze River, but this trend was not continuous; when the total storage capacity reached a certain level, the water temperature did not increase further. If the total storage capacity continues to increase in the future, there will be no significant impact on the discharge water temperature during these months. The discharge water temperature of the TGD was lower than that before the construction of the dam from March to July, and the discharge water temperature trend was different from that between October and February. With the construction of upstream dams, the temperature variation will significantly decrease in March, April, and May, and the variation in the discharge water temperature of the TGD will increase slightly in June and July. Continuous dam construction upstream will weaken the impact of the low-temperature water discharged from TGD.

\section{Conclusions}

The construction of multiple dams had different cumulative impacts on the water temperature downstream. With the construction of Xiangjiaba and Xiluodu, the range of the discharge water temperature of $\mathrm{XJB}$ was reduced, and the occurrence of extreme water temperatures was delayed. From March to August, lower-temperature water (compared to the water temperature before dam construction) was discharged, and higher-temperature water was discharged from November to 
January. Due to the influence of climate and tributaries, the impact of upstream dams was obviously mitigated by more than $48 \%$ at Cuntan, the tail of the Three Gorges reservoir, but it was still observable.

With the construction of the Three Gorges dam, its annual average discharge water temperature increased by $0.2^{\circ} \mathrm{C}$ compared to the natural water temperature. From September to February of the next year, the discharge water temperature (in the 2nd period) was $2.1^{\circ} \mathrm{C}$ higher than that before the construction of the dam (in the 1st period). With the construction of Xiangjiaba and Xiluodu (in the 3rd period), the temperature variation (the discharge water temperature of the TGD minus the natural water temperature at TGD dam) increased to $2.7^{\circ} \mathrm{C}$. After the Baihetan and Wudongde dams are constructed in 2021 (in the 4th period), we believe there will be no further temperature increases from September to February of the next year. In spring (March-May), the water temperature discharged from the Three Gorges (in the 2nd period) was $3.1^{\circ} \mathrm{C}$ lower than that in the 1st period. As the number of dams increased, the discharge water temperature from March to May increased conversely; it seemed that the cumulative effect, even the negative cumulative impact, decreased with the increase of the upstream total storage capacity.

Author Contributions: Conceptualization, T.H. and Y.T.; methodology, T.H. and Y.D.; software, T.H. and Y.Y.; formal analysis, T.H. and N.L.; investigation, T.H.; data curation, Y.D.; writing-original draft preparation, T.H. and Y.T.; writing - review and editing, Y.D. All authors have read and agreed to the published version of the manuscript.

Funding: This research was supported by the National Key R\&D Program of China (grant number 2016YFC502202) and the National Natural Science Foundation of China (grant number 91547211).

Conflicts of Interest: The authors declare that there are no conflicts of interest.

\section{References}

1. Zhou, J.; Zhao, Y.; Song, L.; Bi, S.; Zhang, H. Assessing the effect of the Three Gorges reservoir impoundment on spawning habitat suitability of Chinese sturgeon (Acipenser sinensis) in Yangtze River, China. Ecol. Inform. 2014, 20, 33-46. [CrossRef]

2. Poff, N.L.; Matthews, J.H. Environmental flows in the Anthropocene: Past progress and future prospects. Curr. Opin. Environ. Sustain. 2013, 5, 667-675. [CrossRef]

3. Lu, S.B.; Shang, Y.Z.; Li, W.; Peng, Y.; Wu, X.H. Economic benefit analysis of joint operation of cascaded reservoirs. J. Clean. Prod. 2018, 179, 731-737. [CrossRef]

4. Ma, J.; Liu, Y.; Wang, H. Socioeconomic impacts of hydropower development on the Yibin-Chongqing section, upper reaches of the Yangtze River. Phys. Chem. Earth 2015, 89, 73-78. [CrossRef]

5. Fischer, J.; Lindenmayer, D.B. Landscape modification and habitat fragmentation: A synthesis. Glob. Ecol. Biogeogr. 2007, 16, 265-280. [CrossRef]

6. Zhang, H.X.; Chang, J.X.; Gao, C.; Wu, H.S. Cascade hydropower plants operation considering comprehensive ecological water demands. Energy Convers. Manag. 2019, 180, 119-133. [CrossRef]

7. Magilligan, FJ.; Nislow, K.H. Changes in hydrologic regime by dams. Geomorphology 2005, 71, 61-78. [CrossRef]

8. Yan, H.Y.; Huang, Y.; Wang, G.Y. Water eutrophication evaluation based on rough set and petri nets: A case study in Xiangxi-River, Three Gorges Reservoir. Ecol. Indic. 2016, 49, 463-472. [CrossRef]

9. Long, T.Y.; Wu, L.; Meng, G.H.; Guo, W.H. Numerical simulation for impacts of hydrodynamic conditions on algae growth in Chongqing Section of Jialing River, China. Ecol. Model. 2011, 222, 112-119. [CrossRef]

10. Mao, Z.P.; Wang, Y.C.; Peng, W.Q.; Zhou, H.D. Advances in effects of dams on river ecosystem. Adv. Water Sci. 2005, 16, 134-140. (In Chinese)

11. Tiemann, J.S.; Gillette, D.P.; Wildhaber, M.L.; Edds, D.R. Effects of lowhead dams onriffle-dwelling fishes and macroinvertebrates in a midwestern river. Trans. Am. Fish. Soc. 2004, 133, 705-717. [CrossRef]

12. Liu, L.F.; Cheng, K.Q.; Zhang, S.J.; Liu, C. Study on cumulative effects of water temperature by cascade hydropower stations built on rivers. J. China Inst. Water Resour. Hydropower Res. 2007, 3, 173-180. (In Chinese)

13. Deng, Y.; Li, J.; LI, K.F.; Li, R. Cumulative impact of cascade power stations on water temperature. Adv. Water Sci. 2008, 19, 274-279. (In Chinese) 
14. Liang, R.F.; Deng, Y.; Tuo, Y.C.; LI, J. Analysis on characteristics of water temperature' s cumulative effects of river cascade hydropower stations. J. Sichuan Univ. Eng. Sci. Ed. 2012, 44, 221-227. (In Chinese)

15. Elci, S. Effects of thermal stratification and mixing on reservoir water quality. Limnlogy 2008, 9, 135-142. [CrossRef]

16. Winter, T.; Harvey, J.; Franke, L.; Alley, W. Ground Water and Surface Water: A Single Resource; US Geological Survey Circular: Denver, CO, USA, 2002.

17. Rolland, D.C.; Bourget, S.; Warren, A.; Laurion, I.; Vincent, W.F. Extreme variability of cyanobacterial blooms in an urban drinking water supply. J. Plankton Res. 2013, 35, 744-758. [CrossRef]

18. Ito, Y.; Momii, K. Impacts of regional warming on long-term hypolimnetic anoxia and dissolved oxygen concentration in a deep lake. Hydrol. Process. 2015, 29, 2232-2242. [CrossRef]

19. Gao, X.P.; Zhao, S.X.; Zhang, C.; Tu, X.Y. Index system and method for assessing the health status of river. J. Hydraul. Eng. 2009, 40, 962-968. (In Chinese)

20. Winton, R.S.; Calamita, E.; Wehrli, B. Reviews and syntheses: Dams, water quality and tropical reservoir stratification. Biogeosciences 2019, 16, 1657-1671. [CrossRef]

21. Imberger, J. The diurnal mixed layer. Limnol. Assoc. Sci. Limnol. Oceanogr. 1985, 30, 737-770. [CrossRef]

22. Yang, D.G.; Wei, Q.W.; Chen, X.H.; Liu, J.Y.; Zhu, Y.J.; Wang, K. Hydrological Status of the spawning ground of Acipenser sinensis underneath the Gezhouba Dam and its relationship with the spawning runs. Ecol. Soc. China 2007, 27, 862-869.

23. Olden, J.D.; Naiman, R.J. Incorporating thermal regimes into environmental flows assessments: Modifying dam operations to restore freshwater ecosystem integrity. Freshw. Biol. 2010, 55, 86-107. [CrossRef]

24. Bartholow, J.; Hanna, R.B.; Saito, L.; Lieberman, D.; Horn, M. Simulated limnological effects of the Shasta lake temperature control device. Environ. Manag. 2001, 27, 609-626. [CrossRef] [PubMed]

25. Preece, R.M. Cold Water Pollution below Dams in New South Wales: A Desktop Assessment; NSW Department of Infrastructure, Planning and Natural Resources: Sydney, Australia, 2004.

26. Webe, M.; Rinke, K.; Hipsey, M.R.; Boehrer, B. Optimizing withdrawal from drinking water reservoirs to reduce downstream temperature pollution and reservoir hypoxia. J. Environ. Manag. 2017, 197, 96-105. [CrossRef]

27. Sherman, B.; Todd, C.R.; Koehn, J.D.; Ryan, T. Modelling the impact and potential mitigation of cold water pollution on Murray cod populations downstream of Hume Dam, Australia. River Res. Appl. 2007, 23, 377-389. [CrossRef]

28. Wei, Q.W.; Yang, D.G.; Ke, F.E.; Kynard, B.; Kiefefer, M. Technique of ultrasonic telemetry for Chinese Sturgeon, Acipenser sinensis, in Yangtze River. J. Fish. China 1998, 22, 211-217. (In Chinese)

29. Hu, D.G.; Ke, F.E.; Zhang, G.L. The second survey on the spawning ground of Chinese Sturgeon in the downstreams of Gezhouba Hydroelectric Project. Freshw. Fish. 1985, 3, 22-24.

30. Hu, D.G.; Ke, F.E.; Zhang, G.L. Primary survey on spawning of Chinese Sturgeon in the downstream of Gezhouba Hydroelectric Project. Freshw. Fish. 1983, 3, 15-18.

31. Hu, D.G.; Ke, F.E.; Zhang, G.L. Research on the spawning ground of Chinese Sturgeon in the downstreams of Gezhouba Hydroelectric Project. Freshw. Fish. 1992, 5, 6-10.

32. Yi, Y.J.; Sun, J.; Zhang, S.H. A habitat suitability model for Chinese sturgeon determined using the generalized additive method. J. Hydrol. 2016, 534, 11-18. [CrossRef]

33. U.S. Army Corps of Engineers Hydraulic Engineering Center. HEC-RAS River Systems Analysis User Manual Version 4.1. Available online: https://www.hec.usace.army.mil/software/hec-ras/documentation/ HEC-RAS_4.1_Users_Manual.pdf (accessed on 24 April 2020).

34. Drake, J.; Bradford, A.; Joy, D. Application of HEC-RAS 4.0 temperature model to estimate groundwater contributions to Swan Creek, Ontario, Canada. J. Hydrol. 2010, 389, 390-398. [CrossRef]

35. Cole, T.; Buchak, E.M. CE-QUAL-W2: A Two-Dimensional, Laterally Averaged, Hydrodynamic and Water Quality Model, Version 2.0, User Manual; U.S. Army Corps of Engineers, Waterways Experiment Station: Vicksburg, MS, USA, 1995.

36. Kim, Y.; Kim, B. Application of a 2-Dimensional Water Quality Model(CE-QUAL-W2) to the Turbidity Interflow in a Deep Reservoir (Lake Soyang, Korea). Lake Reserv. Manag. 2006, 22, 213-222. [CrossRef] 
37. Rakesh, K.G.; Emmet, M.O.; Steven, W.E. Calibration, Verification, and an Application of a Two-Dimensional Hydrothermal Model [CE-QUALW2(t)] for Cannonsville Reservoir. Lake Reserv. Manag. 2009, 14, 186-196.

38. Guo, W.X.; Wang, H.X.; Xia, Z.Q. Effects of Three Gorges and Gezhouba reservoirs on river water temperature regimes. J. Hydrol. Eng. 2009, 28, 182-187. (In Chinese)

(C) 2020 by the authors. Licensee MDPI, Basel, Switzerland. This article is an open access article distributed under the terms and conditions of the Creative Commons Attribution (CC BY) license (http://creativecommons.org/licenses/by/4.0/). 